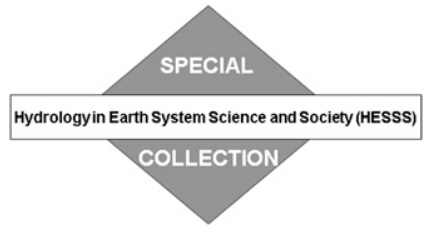

\title{
The Contributions of Precipitation and Soil Moisture Observations to the Skill of Soil Moisture Estimates in a Land Data Assimilation System
}

\author{
Qing LiU, ${ }^{,+}$Rolf H. Reichle, ${ }^{*}$ Rajat Bindlish,,$@$ Michael H. Cosh, ${ }^{\#}$ Wade T. Crow, \\ Richard de Jeu, ${ }^{\&}$ Gabrielle J. M. De LANnOY,****,++ GeOrge J. HufFman, ${ }^{@, \# \#}$ \\ AND THOMAS J. JACKSON \\ * Global Modeling and Assimilation Office, NASA Goddard Space Flight Center, Greenbelt, Maryland \\ ${ }^{+}$Science Applications International Corporation, Beltsville, Maryland \\ \# Hydrology and Remote Sensing Laboratory, Agricultural Research Service, USDA, Beltsville, Maryland \\ @ Science Systems and Applications, Inc., Lanham, Maryland \\ ${ }^{\&}$ Faculty of Earth and Life Science, Department of Hydrology and GeoEnvironmental Sciences, VU Amsterdam, \\ Amsterdam, Netherlands \\ ** Goddard Earth Sciences and Technology Center, University of Maryland, Baltimore County, Baltimore, Maryland \\ ${ }^{++}$Laboratory of Hydrology and Water Management, Ghent University, Ghent, Belgium \\ \#\# Mesoscale Atmospheric Processes Branch, NASA Goddard Space Flight Center, Greenbelt, Maryland
}

(Manuscript received 24 September 2010, in final form 10 February 2011)

\begin{abstract}
The contributions of precipitation and soil moisture observations to soil moisture skill in a land data assimilation system are assessed. Relative to baseline estimates from the Modern Era Retrospective-analysis for Research and Applications (MERRA), the study investigates soil moisture skill derived from (i) model forcing corrections based on large-scale, gauge- and satellite-based precipitation observations and (ii) assimilation of surface soil moisture retrievals from the Advanced Microwave Scanning Radiometer for Earth Observing System (AMSR-E). Soil moisture skill (defined as the anomaly time series correlation coefficient $\mathrm{R}$ ) is assessed using in situ observations in the continental United States at 37 single-profile sites within the Soil Climate Analysis Network (SCAN) for which skillful AMSR-E retrievals are available and at 4 USDA Agricultural Research Service ("CalVal") watersheds with high-quality distributed sensor networks that measure soil moisture at the scale of land model and satellite estimates. The average skill of AMSR-E retrievals is $R=0.42$ versus SCAN and $R=0.55$ versus CalVal measurements. The skill of MERRA surface and root-zone soil moisture is $R=0.43$ and $R=0.47$, respectively, versus SCAN measurements. MERRA surface moisture skill is $R=0.56$ versus CalVal measurements. Adding information from precipitation observations increases (surface and root zone) soil moisture skills by $\Delta R \sim 0.06$. Assimilating AMSR-E retrievals increases soil moisture skills by $\Delta R \sim 0.08$. Adding information from both sources increases soil moisture skills by $\Delta R \sim 0.13$, which demonstrates that precipitation corrections and assimilation of satellite soil moisture retrievals contribute important and largely independent amounts of information.
\end{abstract}

\section{Introduction}

Soil moisture is an important component of the land surface water budget. Large-scale soil moisture data are useful in many research fields such as hydrology, agriculture, and ecology (Robock et al. 1998; Koster et al. 2008; Entekhabi et al. 2010a). Soil moisture is also a critical variable that needs to be carefully initialized for weather

Corresponding author address: Qing Liu, Global Modeling and Assimilation Office, NASA Goddard Space Flight Center, Code 610.1, Greenbelt, MD 20771

E-mail: qing.liu@nasa.gov and climate prediction (Beljaars et al. 1996; Drusch 2007; Mahfouf 2010). In situ measurements of soil moisture, however, are scarce, both spatially and temporally. Regional to global soil moisture data rely largely on simulation with land surface models (LSM) forced by meteorological data (Srinivasan et al. 2000; Dirmeyer et al. 2002) or on satellite observations of active or passive microwaves in the $\mathrm{L}$ - to X-band range (1.4-11 GHz) such as those currently available from the Advanced Microwave Scanning Radiometer for Earth Observing System (AMSR-E; Jackson 1993; Njoku and Entekhabi 1996; Wagner et al. 1999; Owe et al. 2001; Bindlish et al. 2003; Gao et al. 2006). 
Among the surface meteorological forcing inputs to the land model, precipitation has the most direct and important influence on the estimation of soil moisture. Improving precipitation forcing data, in particular through the use of satellite- and gauge-based measurements, can therefore substantially improve the soil moisture estimates from the land surface model (Guo et al. 2006). Model soil moisture estimates can also be improved through the assimilation of soil moisture observations or related variables (such as microwave brightness temperature; Crow et al. 2006; Parajka et al. 2006; de Wit and van Diepen 2007; Reichle et al. 2007; Scipal et al. 2008; Drusch et al. 2009; Li et al. 2010; to name a few). The recently launched Soil Moisture and Ocean Salinity (SMOS) mission (Kerr et al. 2010) and the planned Soil Moisture Active-Passive (SMAP) mission (Entekhabi et al. 2010a) are designed to provide soil moisture measurements with increased accuracy and should thus further enhance the impact of data assimilation on soil moisture estimation.

We would expect that combining the best available precipitation inputs with the assimilation of soil moisture retrievals in a land data assimilation system, if configured properly, should yield the best soil moisture estimates. The exact outcome, however, depends on the characteristics of the land surface model, the data assimilation system, and on the uncertainty of the precipitation inputs and the assimilated soil moisture retrievals. Relative to baseline estimates from the recent Modern Era Retrospectiveanalysis for Research and Applications (MERRA, section 2a), this study assesses the individual and combined contributions of improved precipitation forcing and the assimilation of surface soil moisture retrievals to the skill of soil moisture estimates from a land data assimilation system. A better understanding of these contributions is important for the design of emerging land data assimilation systems and for the development of soil moisture data products for current and future satellite missions.

Our soil moisture skill assessment is based on a network of single-profile, point-scale observations (i.e., one profile of sensors per location) that span the continental United States. We supplement these observations with high-quality in situ measurements from four additional watersheds. The latter are based on multiple in situ measurements distributed within each watershed (section 2c) and have been validated during multiple intensive observational periods. Thus, these estimates can better approximate the scale of the satellite, model, and assimilation estimates. We will demonstrate that our main conclusions do not depend on the unavoidable limitations of the point-scale network.

In the context of the Journal of Hydrometeorology's special collection, "Hydrology in Earth System Science and Society," our results emphasize the need to bring together experts from various communities, including soil moisture remote sensing, precipitation products, and land data assimilation, to achieve the best possible estimates of land surface conditions for applications.

\section{Approach}

In this section we provide an overview of the datasets and experiments. We obtained soil moisture estimates from 12 different land surface model (or assimilation) integrations. The first four are land surface model simulations using four different precipitation forcing datasets (section 2a). The second set of four integrations includes the assimilation of one specific set of AMSR-E soil moisture retrievals (section $2 \mathrm{~b}$ ). The final four integrations are also assimilation integrations, but using a different AMSR-E retrieval dataset (section 2b). Two different datasets of in situ soil moisture measurements are then used to assess the skill of the soil moisture estimates from the satellite, model, and assimilation integrations (section 2c). Skill is measured in terms of the time series correlation coefficient $(R)$ between the anomaly time series of daily average estimates against the in situ observations (section 2d). The use of the (anomaly) $R$ metric emphasizes relative soil moisture variations at daily to weekly time scales and disregards any bias in the absolute values of the mean soil moisture or its variability (Entekhabi et al. 2010b).

\section{a. Land surface model and precipitation forcing}

Model soil moisture was obtained from integrations of the National Aeronautics and Space Administration (NASA) Catchment Land Surface Model (herenafter Catchment model; Koster et al. 2000), which is the land model component of the NASA Goddard Earth Observing System, version 5 (GEOS-5; Rienecker et al. 2008). The model domain consists of the collection of tiles (or Catchment model computational elements) in the continental United States that contain the sites with in situ profile sensors (section 2c). Motivated by the AMSR-E launch in June 2002 and by the availability of the precipitation observations, the 7-yr and 2-month period from 1 June 2002 to 31 July 2009 were chosen as the experiment period. Forcing data for the year 2001 were used to spin up the model through repeated integrations. The time step for the model integrations is $20 \mathrm{~min}$. Atmospheric forcing fields are based on hourly output from the recent NASA Global Modeling and Assimilation Office MERRA reanalysis product (see online at http:// gmao.gsfc.nasa.gov/research/merra), at a resolution of $0.5^{\circ} \times 0.67^{\circ}$ in latitude and longitude, respectively. The Catchment model version and model parameters used here are identical to that of the GEOS-5 version used 
TABLE 1. Overview of precipitation products. The CMAP, GPCP, and CPC products were used to correct MERRA precipitation (section $2 \mathrm{~d}$ ).

\begin{tabular}{llcccc}
\hline \hline Product & \multicolumn{1}{c}{ Version } & Time step & $\begin{array}{c}\text { Spatial resolution } \\
\text { (latitude } \times \text { longitude) }\end{array}$ & Domain & Data type \\
\hline MERRA & N/A & Hourly & $0.50^{\circ} \times 0.67^{\circ}$ & Global & Reanalysis \\
CMAP & "Standard" & Pentad & $2.50^{\circ} \times 2.50^{\circ}$ & Global & Satellite + gauge \\
GPCP & v2.1 & Pentad & $2.50^{\circ} \times 2.50^{\circ}$ & Global & Satellite + gauge \\
CPC & "ll_stdqc_new" & Daily & $0.25^{\circ} \times 0.25^{\circ}$ & Continental United States & Gauge \\
\hline
\end{tabular}

for MERRA data production. MERRA relies on the assimilation of a vast number of conventional and satellite observations of atmospheric fields but does not include a land surface analysis. The assimilation of nearreal-time rain-rate retrievals (Rienecker et al. 2008) over the ocean has a very minor impact on the system. MERRA precipitation estimates over land are thus distinct from the observational precipitation products discussed below.

Three additional precipitation products, listed in Table 1, were used to correct the MERRA precipitation toward gauge- and satellite-based observations. Specifically, we used the National Oceanic and Atmospheric Administration (NOAA) Climate Prediction Center Merged Analysis of Precipitation (CMAP; Xie and Arkin 1997; http://www.esrl.noaa.gov/psd/data/gridded/ data.cmap.html) product ("standard" version), the Global Precipitation Climatology Project (GPCP) version 2.1 pentad product (Huffman et al. 1997; Xie et al. 2003), and the NOAA Climate Prediction Center (CPC) daily unified precipitation analysis over the United States (Higgins et al. 2000; available online at ftp://ftp.cpc.ncep. noaa.gov/precip/wd52ws/us_daily). These corrections result in a total of four different precipitation datasets that were used to force the land model, as shown in the top portion of Fig. 1: (i) standard MERRA precipitation, (ii) MERRA corrected to CMAP, (iii) MERRA corrected to GPCP, and (iv) MERRA corrected to CPC. The remainder of the surface meteorological forcing inputs (including air temperature and humidity, radiation, wind speed, and surface pressure) were taken from MERRA data without applying further observationsbased corrections.

The CMAP and GPCP products are available as pentad averages on a $2.5^{\circ} \times 2.5^{\circ}$ global grid and are based on a merger of satellite measurements (infrared and microwave) with global rain gauge observations from the Global Precipitation Climatology Center (Table 1). The GPCP pentad product is computed by adjusting the pentad CMAP product to monthly GPCP estimates (which differ from the CMAP estimates primarily in the input and processing of the satellite observations and in the approach for combining the satellite and gauge inputs). In contrast, the CPC product is available as daily averages on a $0.25^{\circ}$ grid over the continental United States only and is based entirely on rain gauge measurements (Table 1).

The corrected MERRA precipitation forcings were obtained as follows. First, the hourly MERRA total precipitation was time-averaged and regridded to the scale of the correcting dataset (i.e., to pentad and $2.5^{\circ}$ resolution for CMAP and GPCP corrections, and to daily and $0.25^{\circ}$ resolution for CPC corrections). Next, for each pentad or daily time step and each grid cell, scaling factors were computed by determining the ratio of the correcting dataset to the standard MERRA data (i.e., on the grid and at the time scale of the correcting observations). Finally, the scaling factors were regridded back to the MERRA grid and applied to the MERRA data for each hourly time step within the averaging period, that is, for a given grid cell the same scaling factor was applied to the 120- (24-) hourly MERRA values within a given pentad (day). If for a given grid cell the aggregated MERRA value was zero, the corresponding corrected MERRA precipitation values were set to zero, even if the correcting observations may have indicated nonzero precipitation. The scaling factors derived for total precipitation were used to correct MERRA total precipitation, convective precipitation, and snowfall (all of which are separate forcing inputs to the Catchment model).

Because the CMAP, GPCP, and CPC products (Table 1) are based on precipitation observations from satellites

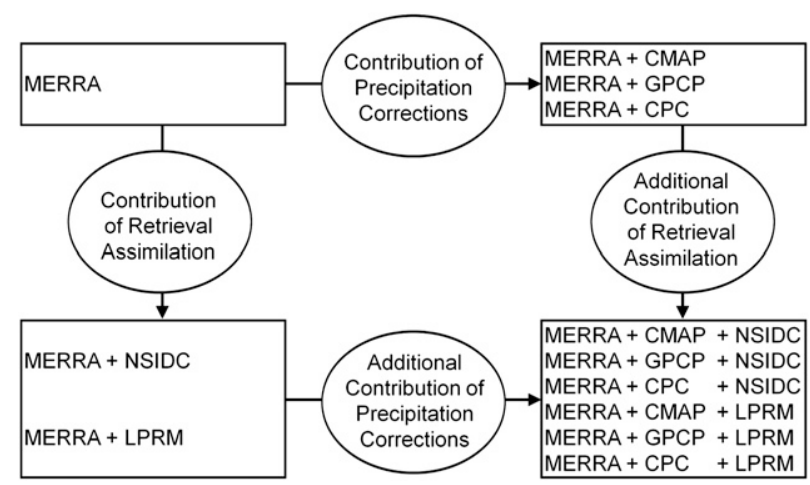

FIG. 1. Overview of model and assimilation integrations and the summary skill analyses of Figs. 4 and 6. 
TABLE 2. Parameters for perturbations to meteorological forcing inputs and Catchment model prognostic variables. Time series correlations were imposed via a first-order autoregressive model [AR(1)].

\begin{tabular}{|c|c|c|c|c|c|c|}
\hline \multirow[b]{2}{*}{ Perturbation } & \multirow{2}{*}{$\begin{array}{l}\text { Additive (A) or } \\
\text { multiplicative (M)? }\end{array}$} & \multirow[b]{2}{*}{ Std dev } & \multirow{2}{*}{$\begin{array}{l}\text { AR(1) time-series } \\
\text { correlation scale }\end{array}$} & \multicolumn{3}{|c|}{ Cross correlation with perturbations in } \\
\hline & & & & $P$ & SW & LW \\
\hline Precipitation $(P)$ & M & 0.5 & 1 day & 1.0 & -0.8 & 0.5 \\
\hline $\begin{array}{l}\text { Downward shortwave } \\
\text { radiation }(\mathrm{SW})\end{array}$ & M & 0.3 & 1 day & -0.8 & 1.0 & -0.5 \\
\hline $\begin{array}{l}\text { Downward longwave } \\
\text { radiation (LW) }\end{array}$ & A & $50 \mathrm{~W} \mathrm{~m}^{-2}$ & 1 day & 0.5 & -0.5 & 1.0 \\
\hline Catchment deficit & A & $0.05 \mathrm{~mm}$ & $3 \mathrm{~h}$ & N/A & & \\
\hline Surface excess & A & $0.02 \mathrm{~mm}$ & $3 \mathrm{~h}$ & & & \\
\hline
\end{tabular}

and/or gauges well beyond the data used in the MERRA precipitation assimilation, we expect that the corrected MERRA precipitation forcing is more accurate than the standard MERRA precipitation product. Hereafter, we refer to the four precipitation forcing datasets (and to the output from the corresponding land model or assimilation integrations) as "MERRA," "CMAP," "GPCP," and "CPC," respectively. Note again, however, that the corrected precipitation datasets are scaled versions of the MERRA precipitation forcing, rather than the CMAP, GPCP, or CPC datasets themselves. Most importantly, the diurnal cycle, the frequency and intensity of rainfall events at the subpentad (or subdaily) scale, and the sub$2.5^{\circ}$ spatial variations (for CMAP and GPCP) are entirely based on MERRA estimates. We did not independently validate the MERRA and corrected MERRA precipitation data at the hourly scale.

\section{b. Soil moisture retrievals and data assimilation}

Two surface soil moisture retrieval products were assimilated into the Catchment model: (i) the operational NASA Level-2B AMSR-E "AE-Land" product (version V09; Njoku 2010) archived at the National Snow and ice Data Center (NSIDC) and (ii) the AMSR-E Land Parameter Retrieval Model (LPRM) product (EASE grid version 03) developed at the VU Amsterdam (Owe et al. 2008). In both cases, we used retrievals based on $\mathrm{X}$-band brightness temperatures from ascending and descending overpasses. We also repeated our analysis with LPRM retrievals based on C-band brightness temperatures (not discussed here) and reached the same general conclusions.

Quality control prior to data assimilation was based on information provided along with the AMSR-E observations and information from the land model. Specifically, we assimilated only NSIDC retrievals that were flagged for light and moderate vegetation, no precipitation, no snow cover, no frozen ground, no radio frequency interference (RFI), and a heterogeneity index of less than $5 \mathrm{~K}$ (based on higher-resolution AMSR-E channels at higher frequencies). The latter criterion excludes soil moisture retrievals that are affected by open water. These criteria are identical to those of Reichle et al. (2007) except that the present study also assimilated soil moisture retrievals with a corresponding AMSR-E flag for moderate vegetation (which were excluded in Reichle et al. 2007). For LPRM we similarly used the quality-control flags that are provided with the retrievals. Additionally, we excluded soil moisture retrievals from assimilation whenever the land surface model indicated active precipitation, frozen soil, or nonzero snow cover.

The 1D ensemble Kalman filter (EnKF) with 12 ensemble members was used to assimilate the satellite retrievals into the model at 3-h intervals (Reichle et al. 2002; Reichle and Koster 2003; Reichle et al. 2007). As mentioned above, separate assimilation integrations were conducted for the NSIDC and the LPRM retrievals. Meteorological forcing inputs and model prognostic variables were perturbed using the perturbations parameter values listed in Table 2 [identical to those of Reichle et al. (2007) after correcting for a typographical error in their Table 2 regarding the standard deviations of the "catchment deficit" and "surface excess" perturbations]. Moreover, we addressed the systematic biases that are typical of satellite and model estimates of soil moisture (Reichle et al. 2004; Reichle and Koster 2004; Drusch et al. 2005; Gao et al. 2007). Prior to data assimilation and separately for NSIDC and LPRM, we (i) scaled the AMSR-E retrievals into the model's climatology and (ii) correspondingly scaled the input observation error standard deviations (Reichle et al. 2007). The retrievals were scaled by matching the cumulative distribution function of the retrievals to that of the model (separately for each location). The input observation error standard deviation for the unscaled retrievals was set to $0.02 \mathrm{~m}^{3} \mathrm{~m}^{-3}$ for NSIDC and $0.08 \mathrm{~m}^{3} \mathrm{~m}^{-3}$ for LPRM, commensurate with the large difference in variability (or dynamic range) in the two products. Prior to data assimilation, these input observation error standard deviations are scaled by the ratio of the soil moisture time 


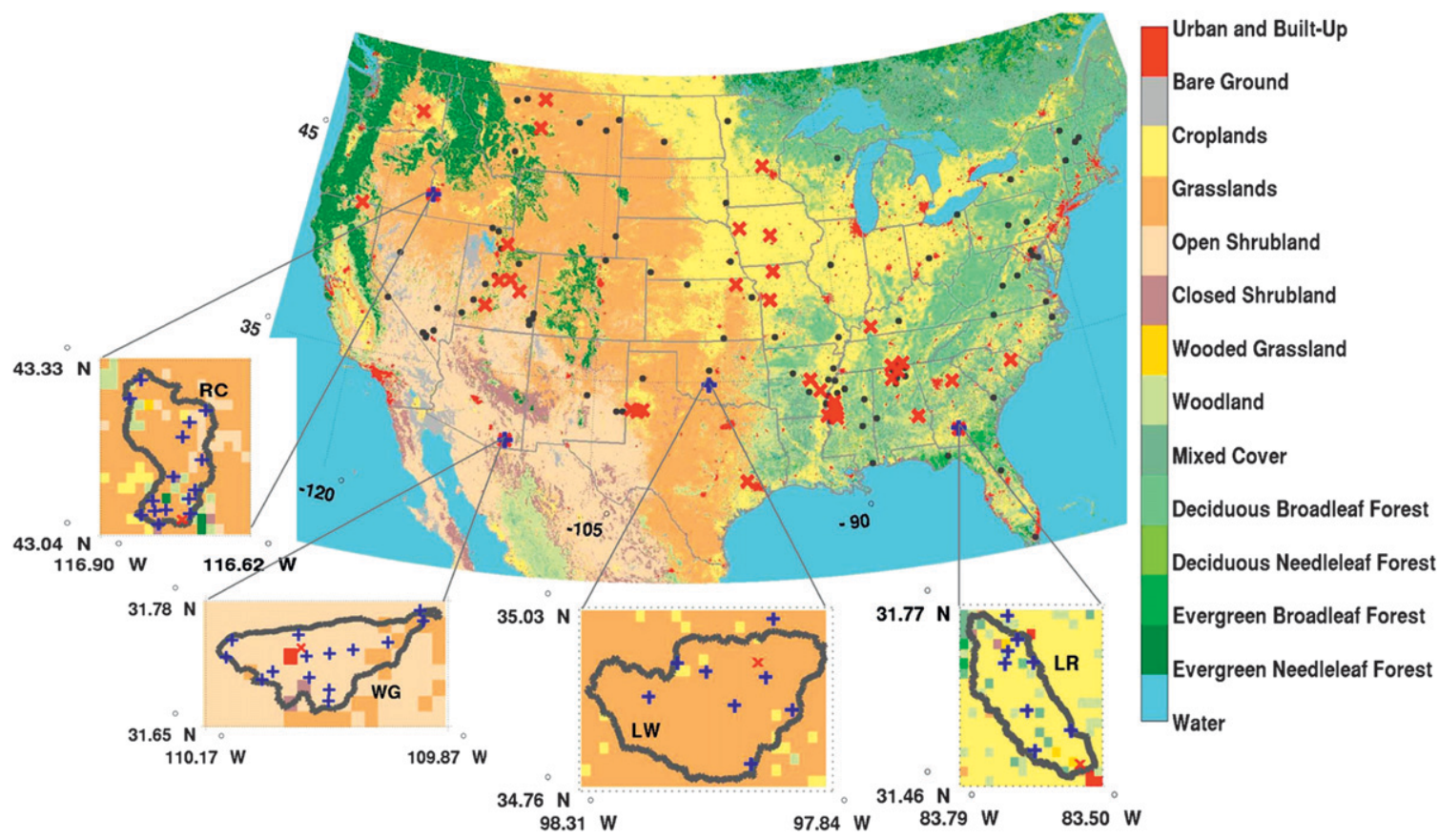

FIG. 2. Location of (crosses) SCAN sites and (plus signs) ARS CalVal watersheds. SCAN sites not used here are marked with dots. The background shows the MODIS land cover product based on UMD classification (see online at http://duckwater.bu.edu/lc/mod12q1.html) at $\sim 2-\mathrm{km}$ resolution.

series standard deviation of the Catchment model to that of the NSIDC (or LPRM) retrievals (separately for each location). After scaling, the observation error standard deviations are similar for NSIDC and LPRM and range from 0.01 to $0.11 \mathrm{~m}^{3} \mathrm{~m}^{-3}$ depending on local climatological conditions, consistent with the values listed in (de Jeu et al. 2008). See section 3c for more discussion of the observation and model error parameters.

\section{c. In situ soil moisture observations}

Two different sets of in situ soil moisture observations were used to analyze the skill of the satellite, model, and assimilation estimates. The first was from the USDA Soil Climate Analysis Network (SCAN, available online at http://www.wcc.nrcs.usda.gov; Schaefer et al. 2007). Hourly soil moisture measurements were taken with a device measuring the dielectric constant of the soil (Stevens Water Hydra Probe sensors inserted horizontally at depths of 5, 10, 20, 50, and $100 \mathrm{~cm}$ wherever possible). There are a total of 123 SCAN sites in the contiguous United States that provide some data during the experiment period (Fig. 2). For data from each SCAN site we applied extensive quality control steps that included automatic detection of problematic observations and a visual inspection of the time series. Specifically, we excluded data that are obviously unrealistic (e.g., excluding data outside of the physically possible range, or data related to discontinuities in the time series that could not be explained by physical processes). We also excluded soil moisture measurements that were taken under frozen conditions (according to SCAN soil temperature measurements), or data affected by inconsistencies that are most likely due to changes in sensor calibration or sensor installation. After quality control of the hourly data, the SCAN observations were aggregated into daily averages.

As will be discussed below (section 2d), we assess skill in terms of time series correlation coefficients for daily average anomalies at times and locations when AMSR-E observations were assimilated. The number of SCAN sites that we could use for skill assessment was therefore constrained by the availability of the assimilated AMSR-E retrievals and by the number of in situ measurements. SCAN sites where either NSIDC or LPRM retrieval skill is substantially worse than the corresponding baseline MERRA skill (specifically, $\Delta R<-0.2$ ) were excluded from the analysis. For instance, SCAN sites located in the northeastern United States were typically excluded from analysis because of missing or poor AMSR-E retrievals, which can be attributed to the usually dense, forested vegetation cover (Fig. 2). At these locations, AMSR-E soil moisture retrievals are of poor quality and should not be assimilated. Eventually, 37 SCAN sites were used to assess the skill of surface soil moisture estimates and 35 of the 37 sites were used to assess the skill of root zone moisture estimates (Fig. 2 and Table 3). The impact of this screening is obviously to exclude 
TABLE 3. Coordinates of SCAN sites. Also shown are the surface soil moisture skill levels of the MERRA, NSIDC, and LPRM estimates and the number of daily average anomalies that contribute to the skill computation (based on joint availability of NSIDC, LPRM, and SCAN in situ data). Boldface $R$ values indicate the maximum among the three listed $R$ values at each site. Sufficient numbers of root zone soil moisture measurements were not available for SCAN sites 2057/AL and 2058/AL.

\begin{tabular}{|c|c|c|c|c|c|c|c|}
\hline \multirow[b]{3}{*}{ Scan ID } & \multirow[b]{3}{*}{ U.S. states } & \multirow[b]{3}{*}{ Lat } & \multirow[b]{3}{*}{ Lon } & \multirow[b]{3}{*}{ No. of data } & \multicolumn{3}{|c|}{ Skill (anomaly $R$ ) } \\
\hline & & & & & \multirow{2}{*}{$\begin{array}{c}\text { Model } \\
\text { MERRA }\end{array}$} & \multicolumn{2}{|c|}{ Satellite (AMSR-E) } \\
\hline & & & & & & NSIDC & LPRM \\
\hline 2115 & $\mathrm{AL}$ & 32.43 & -85.75 & 881 & 0.42 & 0.41 & 0.39 \\
\hline 2058 & $\mathrm{AL}$ & 34.43 & -87.00 & 1282 & 0.42 & 0.31 & 0.29 \\
\hline 2057 & $\mathrm{AL}$ & 34.78 & -86.55 & 1532 & 0.56 & 0.39 & 0.43 \\
\hline 2030 & AR & 34.85 & -91.88 & 843 & 0.53 & 0.52 & 0.50 \\
\hline 2091 & AR & 34.28 & -91.35 & 697 & 0.33 & 0.35 & 0.34 \\
\hline 2026 & $\mathrm{AZ}$ & 31.73 & -110.05 & 1700 & 0.40 & 0.26 & 0.47 \\
\hline 2013 & GA & 33.88 & -83.43 & 1038 & 0.41 & 0.39 & 0.35 \\
\hline 2027 & GA & 31.50 & -83.55 & 1956 & 0.38 & 0.62 & 0.43 \\
\hline 2031 & IA & 42.02 & -93.73 & 1258 & 0.54 & 0.39 & 0.39 \\
\hline 2068 & IA & 42.43 & -95.77 & 1126 & 0.47 & 0.39 & 0.51 \\
\hline 2029 & ID & 43.07 & -116.75 & 1315 & 0.38 & 0.36 & 0.54 \\
\hline 2094 & $\mathrm{KS}$ & 39.70 & -96.16 & 1001 & 0.59 & 0.43 & 0.42 \\
\hline 2005 & KY & 37.10 & -87.83 & 164 & -0.06 & 0.28 & 0.19 \\
\hline 2002 & $\mathrm{MN}$ & 45.42 & -93.95 & 1195 & 0.44 & 0.52 & 0.34 \\
\hline 2061 & MO & 38.87 & -94.03 & 660 & 0.68 & 0.49 & 0.53 \\
\hline 2047 & MO & 40.25 & -93.72 & 887 & 0.59 & 0.41 & 0.47 \\
\hline 2110 & MS & 32.86 & -90.52 & 880 & 0.36 & 0.41 & 0.23 \\
\hline 2032 & MS & 33.38 & -90.65 & 1755 & 0.27 & 0.16 & 0.22 \\
\hline 2109 & MS & 33.66 & -90.57 & 913 & 0.53 & 0.60 & 0.58 \\
\hline 2086 & MS & 33.09 & -90.51 & 690 & 0.45 & 0.54 & 0.46 \\
\hline 2087 & MS & 33.00 & -91.06 & 1041 & 0.52 & 0.32 & 0.37 \\
\hline 2019 & MT & 48.48 & -109.80 & 1521 & 0.56 & 0.49 & 0.59 \\
\hline 2119 & MT & 47.06 & -109.95 & 337 & 0.68 & 0.51 & 0.57 \\
\hline 2074 & OR & 42.02 & -121.39 & 1076 & -0.03 & 0.11 & 0.14 \\
\hline 2037 & $\mathrm{SC}$ & 34.30 & -79.73 & 1639 & 0.14 & 0.38 & 0.43 \\
\hline 2076 & $\mathrm{TN}$ & 35.07 & -86.89 & 1585 & 0.47 & 0.38 & 0.43 \\
\hline 2077 & $\mathrm{TN}$ & 35.14 & -86.19 & 1453 & 0.38 & 0.32 & 0.35 \\
\hline 2016 & TX & 30.08 & -95.98 & 1086 & 0.52 & 0.46 & 0.50 \\
\hline 2106 & $\mathrm{TX}$ & 33.63 & -102.75 & 974 & 0.52 & 0.38 & 0.51 \\
\hline 2104 & TX & 33.62 & -102.04 & 1224 & 0.52 & 0.54 & 0.54 \\
\hline 2105 & TX & 33.55 & -102.37 & 1077 & 0.52 & 0.38 & 0.52 \\
\hline 1056 & UT & 41.22 & -111.29 & 150 & 0.70 & 0.76 & 0.78 \\
\hline 2126 & UT & 39.42 & -111.57 & 184 & 0.44 & 0.54 & 0.27 \\
\hline 2125 & UT & 38.15 & -112.25 & 200 & 0.33 & 0.17 & 0.14 \\
\hline 2131 & UT & 39.02 & -110.16 & 193 & 0.16 & 0.56 & 0.67 \\
\hline 2132 & UT & 39.53 & -110.81 & 208 & 0.20 & 0.35 & 0.38 \\
\hline 2021 & WA & 47.00 & -118.57 & 1496 & 0.43 & 0.45 & 0.44 \\
\hline Avg & & & & 1006 & 0.43 & 0.41 & 0.42 \\
\hline
\end{tabular}

locations for which the skill contribution from precipitation corrections may be dominant, which will be discussed further in section 4.

The second set of in situ observations is from dense sensor networks that are located in four USDA Agricultural Research Service (ARS) experimental watersheds (also shown in Fig. 2) and that were specifically designed for the validation of satellite soil moisture retrievals (Jackson et al. 2010). These four watersheds are hereinafter termed "CalVal" watersheds and include (from west to east) Reynolds Creek, (RC; Idaho), Walnut Gulch (WG; Arizona), Little Washita, (LW; Oklahoma), and Little River (LR; Georgia). At each of the four watersheds, long-term surface soil moisture measurements were collected at hourly (RC) or half-hourly (WG, LW, and LR) intervals using between 8 and 15 sensors per watershed (Stevens Water Hydra Probe sensors inserted horizontally at 5-cm depth), distributed over an area of size similar to that of the AMSR-E satellite footprint. From the individual sensor measurements within each watershed, area-average surface soil moisture measurements were calculated via Thiessen polygon averaging. During a series of field experiments, the CalVal surface soil moisture measurements were shown to be 
representative of the watershed average, with an error on the order of $0.01 \mathrm{~m}^{3} \mathrm{~m}^{-3}$ (Jackson et al. 2010). For this study, we excluded (hourly or half hourly) watershedaveraged CalVal observations if the corresponding soil temperature was below $2^{\circ} \mathrm{C}$ or if fewer than 6 sensors contributed to the watershed average. From the remaining measurements, daily average values were computed if at least $16 \mathrm{~h}$ were observed on a given day.

In each of the four CalVal watersheds there is also an independent SCAN profile sensor, which allows us to assess the impact of using the less-representative but more widely available SCAN observations in our skill assessment of surface soil moisture estimates (section 3b). Unfortunately, sufficiently verified root zone soil moisture measurements from the CalVal watersheds were not available for this study.

\section{d. Skill metric}

Absolute values for soil moisture are difficult to obtain at the global scale, and bias errors (in terms of the mean and in terms of the variability) are common for satellite, model, and in situ soil moisture estimates (Reichle et al. 2004). Besides the above-mentioned discrepancy between the point-scale SCAN measurements and the horizontally distributed satellite, model, and assimilation estimates, there is also a discrepancy in the vertical support of the in situ, satellite, and model/assimilation soil moisture. AMSR-E retrievals of soil moisture are shallowest, representing on average only the top 1-2 cm of the soil column. Catchment model surface soil moisture covers the top $2 \mathrm{~cm}$ of the soil column. In situ surface soil moisture observations (SCAN and CalVal) were taken at 5 -cm depth. Catchment model root zone soil moisture covers the top $1 \mathrm{~m}$ of the soil profile and is validated with a depth-weighted average of the SCAN sensors at 5, 10, and $20 \mathrm{~cm}$, because SCAN data at 50 and $100 \mathrm{~cm}$ were too sparse relative to data for the upper layers. Fortunately, temporal variations (in a percentile sense) are typically more important for model-based applications (Entekhabi et al. 2010b). We therefore assess skill here in terms of time series correlation coefficients for daily average anomalies.

For the results presented here, we computed the average skill across all sites (or watersheds) as follows. First, we computed the monthly mean seasonal climatology for the experiment period at each site and for each dataset. Next, we computed the corresponding daily anomalies by subtracting the seasonal climatology from the soil moisture estimates and then calculated the anomaly $R$ values for each site. Finally, we averaged the $R$ values across all sites. Minimum data requirements were applied as follows. Across the experiment period of $+7 \mathrm{yr}$, we required a minimum of 8 daily averages within a month for computing a monthly mean value; otherwise, the monthly mean was set to a no-data value. We then required at least three valid monthly mean values for a given calendar month for computing monthly climatological values (on which anomalies are based). We also required a minimum of 100 daily average anomalies (from any calendar month) for computing the anomaly $R$ value.

Next, we computed approximate $95 \%$ confidence intervals for the $R$ estimates at each site (or watershed) based on the Fisher $Z$ transform. These confidence intervals depend on the estimated $R$ value and on the number of degrees of freedom, which is approximated here by the number of data points. The approximate 95\% confidence intervals for the average skill estimates across all sites were then computed by averaging the $95 \%$ confidence intervals of the $N$ contributing sites and subsequent division by the square root of $N$. In a separate analysis (not shown here) we also computed $R$ values and corresponding $95 \%$ confidence intervals across all sites by first normalizing the anomalies (with the site- and dataset-specific standard deviation of the anomalies) and then pooling the normalized anomalies from all sites for direct computation of the $R$ values and associated confidence intervals. While the $R$ values and confidence intervals are slightly different with this alternative strategy, we arrived at the same general conclusions. In either case, the $95 \%$ confidence intervals computed here are only an approximation and likely underestimate the true width of the confidence interval because of temporal error correlations, which implies that the number of degrees of freedom is less than the number of data points.

The results presented in section 3 are based on anomaly $R$ values computed from data at times and locations for which NSIDC and LPRM retrievals were assimilated (and whenever in situ measurements were available). This strategy allows us to compare the skill of the NSIDC and LPRM retrievals with that of the model and assimilation integrations. Such masking, however, overestimates the overall skill contribution of the retrieval assimilation relative to that of the precipitation corrections. Unlike precipitation observations, soil moisture retrievals are not always available at regular intervals (e.g., because the soil moisture signal may be seasonally masked by dense vegetation). In section 4 we will discuss the impact of computing the $R$ values based on all nonwinter times and show that the broad conclusions reached in section 3 are not sensitive to the specific temporal mask that is used.

\section{Results}

As outlined in section 2, we assess skill in terms of the anomaly time series correlation coefficient $R$ against in situ measurements from the SCAN sites and the ARS 
CalVal watersheds. While the SCAN measurements are widely distributed over the continental United States, they are also single-profile, point-scale measurements and thus less appropriate for our purposes of validating satellite-scale soil moisture estimates. In contrast, the CalVal in situ measurements match the satellite footprint scale, but are available for only four watersheds. By assessing the skill of the satellite, model, and assimilation estimates against both in situ datasets and combining the results, we can draw more robust conclusions about relative skill levels, and we can isolate the contributions of the precipitation corrections and the assimilation of soil moisture retrievals. To this end, we will first discuss the skill of the satellite, model, and assimilation estimates against the SCAN in situ measurements, which will introduce the main conclusions of our paper (section $3 \mathrm{a}$ ). Thereafter, we will assess the skill of the SCAN observations against the CalVal in situ measurements and then repeat the skill assessment of the satellite, model, and assimilation estimates against the CalVal in situ measurements (section 3b). The salient feature of this second analysis is that we assess skill against SCAN and CalVal in situ measurements based on the same times and locations. The combination of the results of the two skill analyses will corroborate our main conclusions and offer additional insights.

\section{a. Skill assessment against SCAN in situ measurements}

Figure 3 summarizes the skill of the satellite, model, and assimilation estimates when validated against SCAN in situ measurements (section 2c). The black bars in Fig. 3 show the skill (anomaly $R$ ) of the model soil moisture estimates, with skill averaged over 37 SCAN sites for surface soil moisture and over 35 for root zone soil moisture (Fig. 2 and Table 3). As expected, the quality of the precipitation forcing is reflected in the skill of the soil moisture estimates obtained from the land model. Model skill with MERRA precipitation is lowest $(R=0.43$ for surface and $R=0.47$ for root zone soil moisture). CMAP and GPCP precipitation forcing resulted in similarly higher model skills ( $R=0.47$ for surface and $R=0.50$ 0.51 for root zone soil moisture). The highest model skill is obtained with CPC precipitation forcing ( $R=0.51$ for surface and $R=0.55$ for root zone moisture). The relative skill of surface and root zone soil moisture estimates is consistent across the four model datasets (i.e., CPC is most skillful, followed by CMAP and GPCP, and MERRA is least skillful).

When using the MERRA model skill as a baseline, the skill improvements obtained from the CMAP and GPCP precipitation corrections thus are $\Delta R \approx 0.04$ for surface

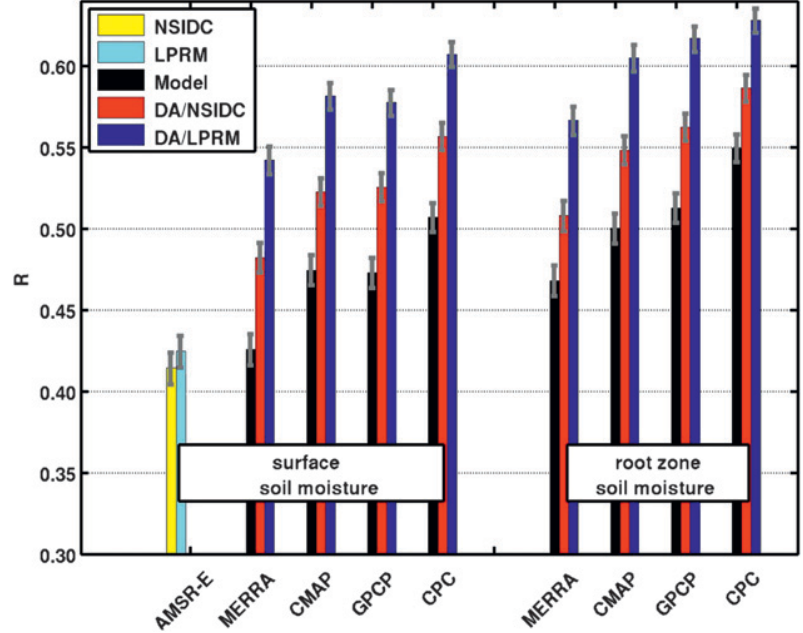

FIG. 3. Average time series correlation coefficient $R$ with SCAN in situ surface and root zone soil moisture anomalies for estimates from two AMSR-E retrieval datasets (NSIDC and LPRM), the Catchment model forced with four different precipitation datasets (MERRA, CMAP, GPCP, and CPC), and the corresponding data assimilation integrations (DA/NSIDC and DA/LPRM). Average is based on 37 SCAN sites for surface and 35 SCAN sites for root zone soil moisture (Table 3). Error bars indicate approximate $95 \%$ confidence intervals

and $\Delta R \approx 0.03-0.04$ for root zone moisture. CPC corrections resulted in higher skill improvements of $\Delta R \approx$ 0.08 for both surface and root zone soil moisture. The approximate $95 \%$ confidence intervals of the $R$ estimates (also shown in Fig. 3 ) are around \pm 0.01 , which indicates that the improvements in skill from the precipitation corrections are statistically significant.

The skill of AMSR-E satellite retrievals of surface soil moisture, shown in the yellow and light blue bars of Fig. 3, is $R=0.41$ for NSIDC, and $R=0.42$ for LPRM. Both are worse than the model skills (e.g., $\Delta R \approx-0.01$ for MERRA, and $\Delta R \approx-0.09$ for CPC). The improvements that can be expected from the assimilation of the AMSR-E retrievals are therefore limited, particularly when precipitation corrections are also applied. Nevertheless, Fig. 3 shows (red and blue bars) that on average data assimilation improves the skill of the model estimates in all cases. Assimilating LPRM retrievals generally yields greater improvements than assimilating NSIDC retrievals. When comparing the skill of each assimilation integration with the skill of the corresponding model integration (with same precipitation forcing), the improvement from the assimilation of AMSR-E soil moisture retrievals ranges from skill improvements of $\Delta R \approx 0.04$ (for root zone moisture with CPC precipitation and NSIDC retrievals) to $\Delta R \approx 0.12$ (surface moisture with MERRA precipitation and LPRM retrievals). As expected (Reichle et al. 2008 b), the skill improvement from the assimilation of 
soil moisture retrievals is greatest when the model is least skillful (MERRA). The approximate $95 \%$ confidence intervals of the $R$ estimates are around \pm 0.01 and indicate that the skill improvements from the retrieval assimilation are statistically significant.

From the results shown in Fig. 3 we can now summarize the soil moisture skill improvements from better precipitation forcing, assimilation of AMSR-E soil moisture retrievals, and their combination. Figure 1 outlines how the skill contributions are summarized. The model-only integration with uncorrected MERRA forcing serves as the baseline (top-left corner of Fig. 1). The skill contribution from precipitation corrections was then computed as the average of the differences between model skill with corrected precipitation forcing (CMAP, GPCP, and CPC; top-right corner of Fig. 1) versus the baseline MERRA skill, computed separately for surface and root zone soil moisture. Similarly, the contribution of retrieval assimilation was computed as the average of the skill difference between the assimilation estimates without precipitation corrections (i.e., with MERRA precipitation forcing; bottom-left corner of Fig. 1) and the baseline MERRA estimates. The additional contribution of precipitation corrections over and above retrieval assimilation is computed by differencing the (average) skill of the full system (with precipitation corrections and retrieval assimilation; bottom-right corner of Fig. 1) and the skill of the retrieval assimilation without precipitation corrections (bottom-left corner of Fig. 1). Likewise, we also compute the additional contribution of retrieval assimilation over and above precipitation corrections by differencing the (average) skill of the full system (bottom-right corner of Fig. 1) and the average skill of the model-only integrations with precipitation corrections (top-right corner of Fig. 1).

Figure 4 shows the summary skill analysis against SCAN measurements. The (average) skill improvement from precipitation corrections is $\Delta R \approx 0.06$ for surface and $\Delta R \approx 0.05$ for root zone soil moisture. Greater skill improvements of $\Delta R \approx 0.09$ for surface and $\Delta R \approx 0.07$ for root zone soil moisture are realized through retrieval assimilation. Moreover, precipitation corrections and retrieval assimilation contribute largely (although not entirely) independent information, which is evidenced by the additional skill improvement when both precipitation corrections and retrieval assimilation are employed. Specifically, additional skill improvements from adding the retrieval assimilation to precipitation corrections are around $\Delta R \approx 0.08$ for surface and $\Delta R \approx 0.07$ for root zone soil moisture. Additional skill improvements from adding the precipitation corrections to retrieval assimilation are around $\Delta R \approx 0.05$ for surface and root zone soil moisture. Consequently, the combined skill improvements from precipitation corrections and retrieval

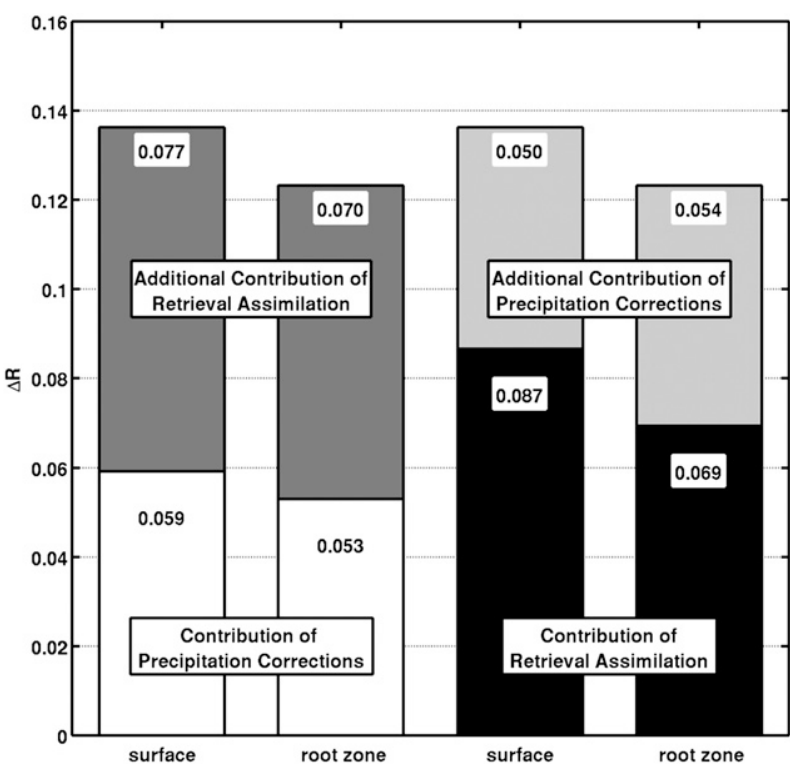

FIG. 4. Average skill (anomaly correlation coefficient) improvement over model estimates from precipitation corrections and retrieval assimilation when validated against SCAN in situ measurements of (first and third bars from left) surface and (second and fourth bars from left) root zone soil moisture. The two left bars show the average skill improvement from precipitation corrections and the additional improvement from retrieval assimilation. The two right bars show the average skill improvement from retrieval assimilation and the additional skill from precipitation corrections (see text for details).

assimilation are considerable ( $\Delta R \approx 0.14$ for surface and $\Delta R \approx 0.12$ for root zone moisture) .

\section{b. Comparison of SCAN and CalVal in situ measurements and associated skill values}

The SCAN measurements are an attractive choice for assessing the skill of our soil moisture estimates because of the availability of both surface and root zone soil moisture measurements, the relatively long data record, and the wide distribution across the continental United States. However, the SCAN measurements also suffer from a key disadvantage. At each SCAN site, there is only one profile of sensors measuring soil moisture at the point scale, which stands in stark contrast to the distributed $\sim 40-\mathrm{km}$ scale of the satellite, model, and assimilation estimates. Moreover, resource constraints limited the amount of data quality control performed by the SCAN data providers. Even though the SCAN measurements were considered to be the validating "truth" in the previous section, they are thus themselves subject to considerable measurement uncertainties and representativeness errors.

In contrast, in situ observations from the four ARS CalVal watersheds offer soil moisture estimates at a scale that is more appropriate for assessing the skill of satellite, 
TABLE 4. Anomaly time series correlation coefficient of surface soil moisture from SCAN and CalVal measurements and their approximate $95 \%$ confidence intervals for the four CalVal watersheds (RC, WG, LW, and LR). The final column shows the $R$ value averaged over the four locations.

\begin{tabular}{|c|c|c|c|c|c|}
\hline ARS CalVal watershed ID & $\mathrm{RC}$ & WG & LW & LR & \\
\hline SCAN site ID & 2029 & 2026 & 2023 & 2027 & \\
\hline U.S. states & ID & $\mathrm{AZ}$ & $\mathrm{OK}$ & GA & Avg \\
\hline No. of daily average data & 1304 & 1553 & 1760 & 2442 & 1765 \\
\hline Anomaly $R$ & $0.84 \pm 0.02$ & $0.73 \pm 0.02$ & $0.68 \pm 0.02$ & $0.79 \pm 0.01$ & $0.76 \pm 0.01$ \\
\hline
\end{tabular}

model, and assimilation estimates. These estimates are based on extensive knowledge of local conditions and have been processed to a high degree of quality. However, there are only four CalVal watersheds. Moreover, root zone soil moisture measurements of a comparably high level of quality are not readily available for this study at present.

In this section, we first assess the quality of the pointscale SCAN in situ measurements taken in the four CalVal watersheds against the corresponding (satellite scale) CalVal in situ measurements. Thereafter, we repeat the previous section's skill assessment of the satellite, model, and assimilation estimates against both SCAN and CalVal in situ measurements. Most importantly, we compute $R$ values based on exactly the same times and locations for both in situ data sources.

First, Table 4 shows the skill (in terms of anomaly $R$ ) of the SCAN against the CalVal in situ measurements of surface soil moisture for the four CalVal watersheds. The average skill of the SCAN in situ measurements is $R=0.76$, ranging from $R=0.68(\mathrm{LW})$ to $0.84(\mathrm{RC})$. Such high (anomaly) correlation between the two in situ datasets is a first indication that the SCAN measurements are indeed useful for assessing the skill of satellite, model, and assimilation estimates. (Note that the $R$ values of Table 4 were computed without masking to NSIDC or LPRM retrievals. We obtain very similar $R$ values if we consider in situ measurements only at times when NSIDC and LPRM retrievals are also available.)

Next, we compare the skill of surface soil moisture estimates from the AMSR-E retrievals, model integrations, and assimilation estimates separately against the two in situ datasets. For this analysis, a common space-time mask was applied based on the joint availability of SCAN, CalVal, NSIDC, and LPRM data. Figure 5 shows anomaly $R$ values averaged over the four CalVal watersheds for all model and assimilation integrations (including SCAN site 2023 in the LW watershed, which was excluded from the results in Fig. 3 because at this location $\Delta R<-0.2$ for SCAN; section 2c). It is immediately obvious from Fig. 5 that the (anomaly) $R$ values against the CalVal data are overall considerably higher than the (anomaly) $R$ values against SCAN data, by $\Delta R \approx 0.09-0.15$ for satellite, model or assimilation skills. This difference primarily reflects the errors in the SCAN data that are due to the mismatch between the point scale of the in situ measurements and the distributed scale of the satellite, model, and assimilation estimates. The CalVal measurements are averages over multiple sensors and therefore less noisy and more spatially representative, resulting in higher skill numbers (in terms of anomaly $R$ ) when used to validate the distributed satellite, model, and assimilation estimates.

Regardless of the obvious differences in their magnitudes, both sets of skill numbers (left and right groups of bars in Fig. 5) show very similar patterns of relative skill for the CalVal watersheds: (i) precipitation corrections (CMAP, GPCP, and CPC) improve model soil moisture skills (over MERRA precipitation forcing), and the improvement is similar for the three corrected precipitation

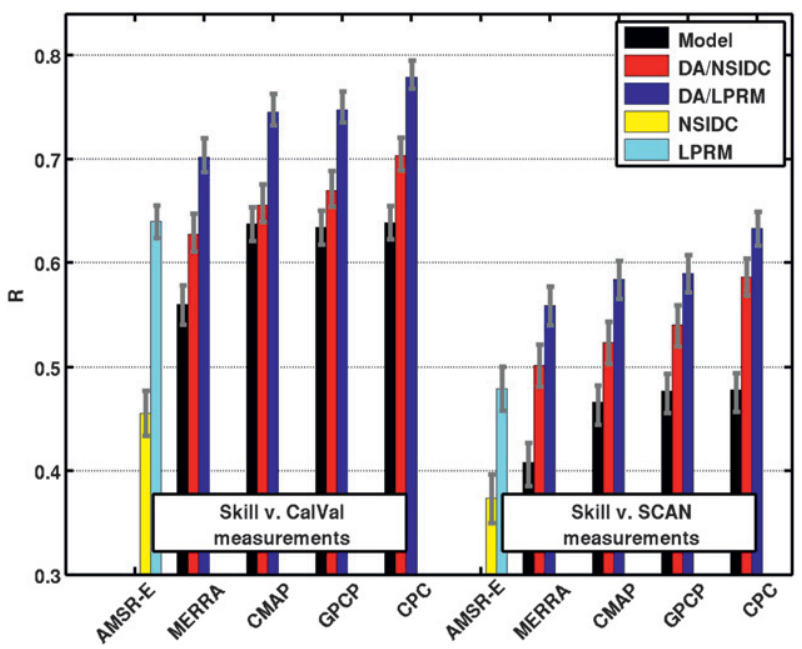

FIG. 5. Average time series correlation coefficient $R$ over ARS CalVal watersheds vs (left group of bars) CalVal and (right group of bars) SCAN surface soil moisture anomalies for estimates from AMSR-E retrievals (NSIDC and LPRM), the Catchment model forced with four different precipitation datasets (MERRA, CMAP, GPCP, and CPC), and the corresponding assimilation integrations (DA/NSIDC and DA/LPRM). Error bars indicate approximate $95 \%$ confidence intervals. The $R$ values are based on a common space-time mask for SCAN and CalVal measurements and for SCAN include only the four SCAN sites collocated with CalVal watersheds. 


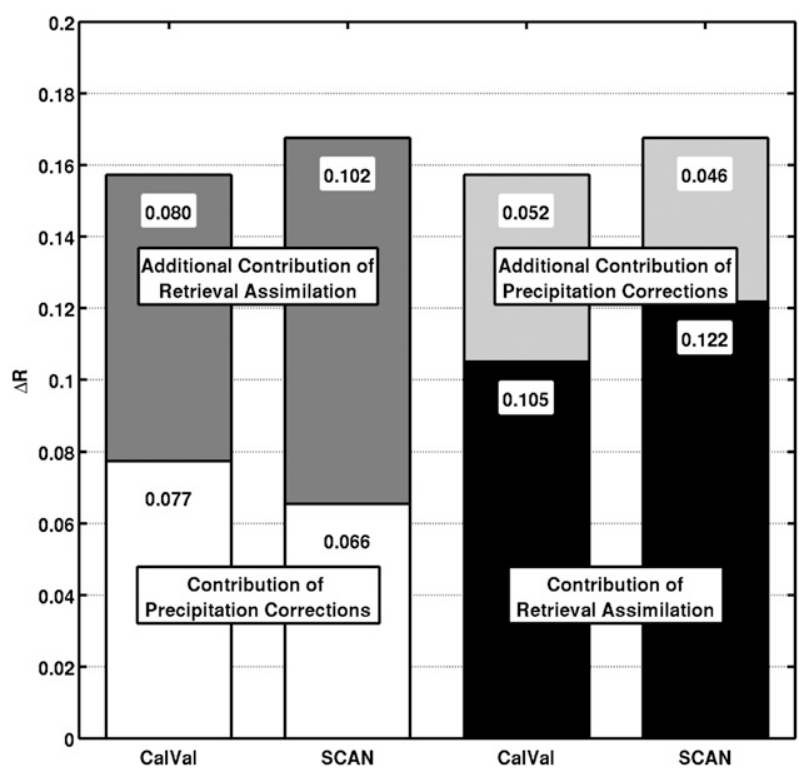

FIG. 6. Average skill improvement over model estimates of surface soil moisture from precipitation corrections and retrieval assimilation when validated against (first and third bars from left) CalVal or (second and fourth bars) corresponding SCAN in situ measurements.

datasets; (ii) NSIDC retrieval skill is worse than model skill; (iii) LPRM retrieval skill is greater than that of the baseline MERRA estimates, and comparable with the model estimates using CMAP, GPCP or CPC corrected precipitation; (iv) nevertheless, retrieval assimilation always improves over the skill of the model; (v) the LPRM retrieval assimilation skill is consistently higher than that of the NSIDC retrieval assimilation, due to the higher skill of the LPRM in the CalVal watersheds (in terms of the anomaly $R$ metric); and (vi) the largest improvements from retrieval assimilation are realized when the model is forced with MERRA and, surprisingly, CPC precipitation. On closer inspection, we found that the CPC precipitation corrections for the LW watershed resulted in the largest improvements in model soil moisture most of the time, but also produced a large overestimation of soil moisture for about a dozen daily averages. These extreme outliers reduce the overall skill of the CPC integration to the level of the CMAP and GPCP integrations. The assimilation of satellite retrievals effectively removed the outliers and consequently resulted in large improvements over the model skill.

Finally, we again condense the results by translating the improvements shown in Fig. 5 into a summary plot. Figure 6 compares the contributions of precipitation corrections and retrieval assimilation to the skill of surface soil moisture when evaluated against the two sets of in situ measurements using a common mask. The combined skill improvement from precipitation corrections and retrieval assimilation is very similar for validation against measurements from CalVal $(\Delta R \approx 0.16)$ and $\operatorname{SCAN}(\Delta R \approx$ $0.17)$. The contribution of precipitation corrections alone to the skill improvement is comparable when evaluated against CalVal measurements $(\Delta R \approx 0.08)$ or against SCAN measurements $(\Delta R \approx 0.07)$. The contribution of retrieval assimilation is also comparable for both in situ datasets $(\Delta R \approx 0.11$ for CalVal and $\Delta R \approx 0.12$ for SCAN $)$. Consequently, the additional contributions from adding precipitation corrections on top of retrieval assimilation (or vice versa) are also comparable. The additional skill improvement from precipitation corrections is $\Delta R \approx$ 0.05 versus either CalVal or SCAN measurements. The additional skill improvement from retrieval assimilation is $\Delta R \approx 0.08$ versus CalVal and $\Delta R \approx 0.1$ versus SCAN measurements.

In summary, Fig. 6 demonstrates that using CalVal or SCAN in situ measurements yields comparable absolute and relative surface soil moisture improvements from precipitation corrections and retrieval assimilation, despite the difference in quality between the two in situ datasets and the apparent difference in the absolute levels of skill (Fig. 5). The general consistency of the skill improvement results based on the two different in situ datasets indicates that the SCAN measurements can in fact be used to assess the relative contributions of precipitation corrections and retrieval assimilation to the skill of surface soil moisture estimates over a wider range of locations. Typically, root zone soil moisture has less spatial variability than surface soil moisture. By implication, using single-profile SCAN sites for the assessment of skill improvements (in terms of the anomaly $R$ metric) should thus also be possible. The results of this section corroborate our main result of section 3a and Fig. 4: precipitation corrections and retrieval assimilation contribute important and largely independent amounts of information to the soil moisture estimates.

\section{c. Data assimilation diagnostics}

The contribution of the retrieval assimilation to the skill improvement of model soil moisture estimates depends on the calibration of the data assimilation system. The skill improvements documented above suggest that our system is adequately calibrated, although not necessarily optimal. We can shed more light on this issue by examining internal diagnostics from the data assimilation system (see Reichle et al. 2002, 2010 for details). Here, we analyze two diagnostics based on the sequence of innovations, or observation-minus-forecast residuals. For a filter that operates according to its underlying assumptions (that various linearizations hold, and that model and observation errors are unbiased, uncorrelated and normally distributed), the time average of the (ensemble 

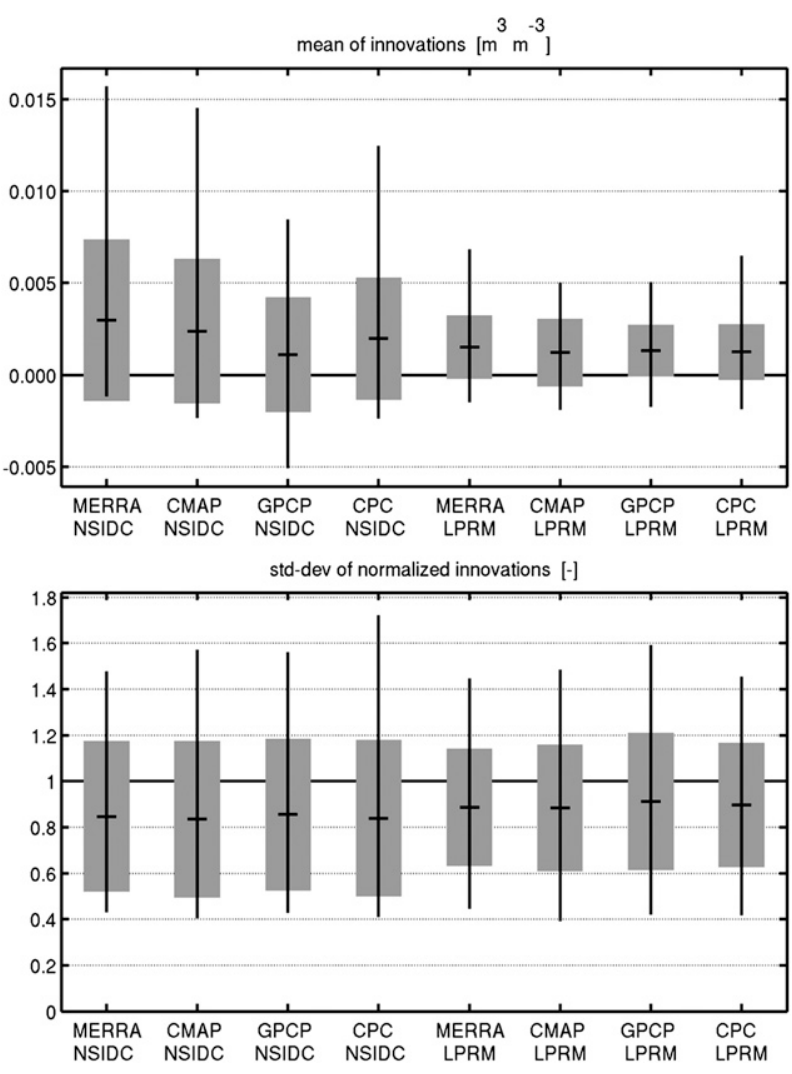

FIG. 7. (top) Mean of innovations $\left(\mathrm{m}^{3} \mathrm{~m}^{-3}\right)$ and (bottom) standard deviation of normalized innovations (dimensionless) for surface soil moisture from integrations that assimilate (first group of four box plots) NSIDC retrievals or (second group of four box plots) LPRM retrievals. Each box plot indicates the average, standard deviation, minimum, and maximum of the respective innovations diagnostic across the 37 SCAN sites.

mean) innovations sequence equals zero. Moreover, the standard deviation of the "normalized" innovations equals 1 . The latter diagnostic compares the actual spread in the innovations to what the filter expects. A simple interpretation is that the assumed error bars of a model forecast and its corresponding observation must have an appropriate overlap.

Of particular interest here is the relative performance of the NSIDC and LPRM assimilation integrations. Figure 7 displays the distribution of the two internal filter diagnostics across the 37 SCAN sites used in the skill assessment of section 3a. The top panel indicates that despite the a priori scaling of the NSIDC and LPRM retrievals, minor biases of up to $\sim 0.015 \mathrm{~m}^{3} \mathrm{~m}^{-3}$ persist at some sites. The large climatological differences between NSIDC retrievals and Catchment model estimates (not shown) imply that the a priori scaling approach (section $2 b)$ for the NSIDC retrievals relies more heavily on higherorder moments of the cumulative distribution functions (when compared to the scaling of LPRM retrievals into the Catchment model climatology). Because of data availability constraints, estimates of these higher-order moments are more uncertain than those for lower-order moments (such as the mean and variance), which may explain the slightly larger innovations bias values of the NSIDC assimilation integrations (when compared to the bias values of the LPRM assimilation integrations).

The standard deviation of the normalized innovations, shown in the bottom panel of Fig. 7, is typically below the target value of 1 . This indicates that the model and/ or the observation error standard deviations were overestimated. Again, the NSIDC assimilation integrations exhibit slightly less optimal innovations statistics, which is again consistent with the large climatological differences between the NSIDC retrievals and the Catchment model estimates. A closer inspection (not shown) reveals that for six SCAN sites (2057/AL, 2058/AL, 2115/AL, 2013/GA, $2076 / \mathrm{TN}$, and $2077 / \mathrm{TN}$ ) the time series standard deviation of NSIDC retrievals is just $0.01 \mathrm{~m}^{3} \mathrm{~m}^{-3}$, which is smaller by a factor of 5 than that of the Catchment model surface soil moisture and thus leads to large values of the scaled observation error standard deviation (input to the assimilation system, section $2 \mathrm{~b}$ ) and thus small values of the normalized innovations variance. If we remove these six SCAN sites from the analysis, the differences in the normalized innovations variances between NSIDC and LPRM vanish (not shown), while the relative improvements of section $3 \mathrm{a}$ are largely unchanged. In any case, the fact that the innovations diagnostics are roughly comparable for the NSIDC and LPRM assimilation integrations indicates that the assimilation performance (relative to its unknown optimum) is comparable for the two retrieval datasets, which lends further support to the broad conclusions reached in this paper.

\section{Discussion and conclusions}

Precipitation is the dominant source of temporal variability for soil moisture. Thus, the most straightforward way to improve soil moisture estimates from land surface models is to improve their precipitation forcing (Gottschalck et al. 2005; Guo et al. 2006; Kato et al. 2007). Our study indicates that large-scale soil moisture estimates can be enhanced by using precipitation observations to correct MERRA reanalysis precipitation and then forcing the land model offline with the corrected precipitation. As expected, corrections based on more accurate precipitation observations (such as the gauge-based, daily, $0.25^{\circ} \mathrm{CPC}$ product) provide greater improvements than corrections based on global-scale products (such as the satellite- and gauge-based, pentad, $2.5^{\circ}$ CMAP and GPCP products), with average skill improvements of $\Delta R \approx 0.06$ for surface and $\Delta R \approx 0.05$ 
for root zone soil moisture (in terms of improvements in the anomaly correlation coefficient $R$ over the skill of the baseline MERRA estimates).

Future experiments could be designed to investigate whether CPC corrections are superior to CMAP or GPCP corrections because of (i) better quantitative accuracy, (ii) higher spatial resolution, and/or (iii) finer temporal resolution. In this study, precipitation corrections were limited to daily (CPC) or pentad (CMAP and GPCP) totals. By further correcting known problems of the reanalysis precipitation (in the diurnal cycle and in the frequency and intensity of rainfall events), additional gains in soil moisture skill may be realized, but this is left for future studies. Similarly, observations-based corrections to forcing variables other than precipitation (primarily incident shortwave radiation) may yield additional gains in the accuracy of model-based soil moisture estimates.

The United States has a dense network of precipitation gauge observations. For regions with sparse precipitation observations, the skill improvement from precipitation corrections could be smaller because fewer precipitation observations are available. In such regions, however, there are also typically fewer radiosonde and aircraft observations that support the atmospheric analysis, thus leading to lower-quality baseline precipitation estimates and leaving more room for improvement. The relative importance of precipitation corrections and retrieval assimilation could therefore be smaller or larger in data-sparse regions. Unfortunately, soil moisture observations are typically also unavailable for such regions, making it impossible to assess soil moisture skill.

This study focuses on long-term precipitation products that are available for the entire MERRA period (1979present). Current generation high-resolution products (Joyce et al. 2004; Huffman et al. 2007) and future products from the planned Global Precipitation Measurement (GPM) constellation of satellites should estimate global precipitation with improved accuracy and space-time coverage (Smith et al. 2007). This should enable additional gains in the skill of model-based soil moisture estimates at the global scale. In any case, it is very encouraging that the demonstrated improvements can be achieved through very simple and computationally inexpensive precipitation corrections using currently available longterm global data products.

Assimilating satellite retrievals of surface soil moisture into the land surface model can further enhance the skill of soil moisture estimates, but the required land data assimilation systems are much more complex and computationally challenging than the above-mentioned precipitation corrections. Assimilation of AMSR-E surface soil moisture retrievals yielded skill improvements of
$\Delta R \approx 0.09$ for surface and $\Delta R \approx 0.07$ for root zone soil moisture, even though the assimilated AMSR-E retrievals were on average worse (by $\Delta R \approx-0.01$ ) than even the baseline model estimates. The relative improvements from precipitation corrections and retrieval assimilation are comparable when measured against two independent sets of in situ observations (SCAN and CalVal). The improvements are also consistent with previous studies (Reichle et al. 2007, 2008b). Such skill improvement from satellite retrievals of soil moisture is essential for regions with sparse or unreliable precipitation observations (Crow 2003).

Naturally, the magnitude of the improvement from satellite soil moisture retrieval assimilation depends on the quality of the retrievals. Based on updated data inputs and the latest version of the GMAO land data assimilation system, the analysis in this paper confirms our previous finding (Reichle et al. 2007) that land model estimates of soil moisture are generally superior to AMSR-E satellite retrievals in terms of the anomaly $R$ metric (provided adequate precipitation forcing data are available). Careful quality control of the assimilated retrievals and/or appropriate adjustments to the observation and model error parameters are thus required to realize the gains noted above. If the quality of the assimilated retrievals is not properly accounted for, the assimilation estimates may well be worse than the model estimates, resulting in a net loss of soil moisture information.

The noted improvements from precipitation corrections are average gains over 37 SCAN sites across the continental United States and are not necessarily realized at individual sites. Besides the obvious selection of locations with low and moderate vegetation (largely based on quality control of the AMSR-E observations), we did not detect any geographical pattern related to land cover or soil types in the skill improvement values. Additional sensitivities in the improvements, for example, to vegetation water content or the type of precipitation (convective vs large scale), are left for future studies.

In this context it is also important to recognize that AMSR-E was not designed specifically for measuring soil moisture, and that it is still an open question how soil moisture can best be retrieved from AMSR-E or similar observations of opportunity, including passive and active (radar) microwave measurements at the $\mathrm{C}$ and $\mathrm{X}$ band (Njoku et al. 2003; Jackson et al. 2004, 2010; Gao et al. 2006; de Jeu et al. 2008; Bartalis et al. 2007). The advent of newer satellite instruments that acquire L-band microwave observations (primarily SMOS and SMAP) will alleviate this constraint and should yield more robust skill improvements. Moreover, the skill improvements from data assimilation documented here are not necessarily optimal. Additional gains in skill may be possible 
through further refinements in the quality control module and through further tuning of the model and observation error parameters that are inputs to the assimilation system (Crow and Reichle 2008; Reichle et al. 2008a; Crow and Van den Berg 2010), but this is left for future studies.

It is no surprise that the combination of precipitation corrections and retrieval assimilation generates the largest improvement in the skill of soil moisture estimates. Figure 4 illustrates that the additional contributions of retrieval assimilation over precipitation corrections ( $\Delta R \approx 0.08$ for surface and $\Delta R \approx 0.07$ for root zone soil moisture) or precipitation corrections over retrieval assimilation $(\Delta R \approx 0.05$ for surface and root zone soil moisture) are only somewhat smaller than the individual contributions themselves, indicating that each of the two sources contribute largely independent information.

As can be expected as a result of the single-profile, point-scale character of the SCAN in situ observations, skill levels of satellite, model, and assimilation estimates are generally lower when measured against SCAN observations than when measured against CalVal observations. Nevertheless, the relative skill contributions of precipitation corrections and retrieval assimilation are remarkably similar, regardless of whether skill is measured against the SCAN or the CalVal observations. The combined results from the skill analyses against the SCAN and the CalVal in situ measurements suggest that the conclusions drawn from the SCAN network with its wider coverage are sensible.

As mentioned in section $2 \mathrm{~d}$, the present study may overestimate the skill contributed by the soil moisture retrieval assimilation for two reasons: For the computation of the $R$ values (i) we selected only SCAN sites with skillful AMSR-E retrievals and (ii) we used only times and locations for which AMSR-E retrievals were assimilated. We addressed the sensitivity of our conclusions to the latter issue by repeating the analysis with a different mask that screens out only cold season processes, regardless of the availability of AMSR-E retrievals ("nonwinter" mask). Specifically, we only excluded data from the computation of the $R$ values for which the baseline MERRA model estimates indicated that the ground was frozen or snow covered. Put differently, times for which AMSR-E retrievals were not assimilated will now also contribute to the skill metric. With this nonwinter mask, we obtain skill improvement values (not shown) that are very similar to those discussed in section $3 \mathrm{a}$ and Fig. 4.

Of course, the analysis with the nonwinter mask still only considers the 37 SCAN sites for which at least 100 AMSR-E retrievals of acceptable skill were available during the +7 -yr experiment period (section $2 b$ ). If we also included sites for which soil moisture retrievals are never available (e.g., densely forested areas or locations with prohibitive radio-frequency interference), the contribution of precipitation corrections (relative to retrieval assimilation) may be enhanced. To increase the impact of retrieval assimilation in such locations, the 1D EnKF used here could be replaced with a distributed (3D) assimilation approach (Reichle and Koster 2003). Given the limited spatial error correlation distances, however, we do not expect that a distributed filter could make up for the lack of soil moisture retrievals in areas where AMSR-E retrievals are not skillful.

Based on SCAN in situ measurements only, our study suggests that the assimilation of surface soil moisture retrievals improves root zone soil moisture, confirming earlier results (Reichle et al. 2007). A more thorough assessment of root zone estimates based on distributed (multiprofile) in situ estimates is left for future study, pending the availability of corresponding high-quality in situ measurements. To this end, root zone estimates from a dense sensor network are needed, similar to the CalVal data used here for surface soil moisture.

The main conclusions of this study are that (i) satelliteand gauge-based precipitation corrections and (ii) the assimilation of surface soil moisture observations contribute important and largely (although not entirely) independent information to the skill of soil moisture estimates from a land data assimilation system. At present, the combination of state-of-the-art precipitation products and soil moisture satellite retrievals (or corresponding microwave observations) in a land data assimilation system can already provide considerable improvements in global soil moisture data products. Additional gains may be realized through the joint assimilation of surface soil moisture retrievals from active microwave sensors (such as the Advanced Scatterometer) and passive microwave sensors (such as AMSR-E) because the two systems have complementary strengths (Liu et al. 2010). Looking ahead, improved data products of soil moisture (based on current and future L-band active and passive microwave satellite observations) and of precipitation (from GPM and from higher-resolution atmospheric modeling and analysis), along with improvements in land surface models and data assimilation systems should further enhance surface and root zone soil moisture estimates at the global scale.

Acknowledgments. Funding for this work was provided by the NASA Earth System Science Research using Data and Products from the Terra, Aqua, and ACRIMSAT Satellites program and the NASA Soil Moisture Active Passive mission project. Gabrielle De Lannoy is a postdoctoral research fellow supported by the Research Foundation Flanders (FWO), Belgium. 
Computing was supported by the NASA High End Computing Program. We are grateful for access to the many datasets that supported this work and highly appreciate the personnel at USDA/ARS, NASA GSFC, NOAA/CPC, Deutscher Wetterdienst, NSIDC, and VU Amsterdam who made them possible. Helpful comments were provided by Pingping Xie and three anonymous reviewers.

\section{REFERENCES}

Bartalis, Z., W. Wagner, V. Naeimi, S. Hasenauer, K. Scipal, H. Bonekamp, J. Figa, and C. Anderson, 2007: Initial soil moisture retrieval from the METOP-A Advanced Scatterometer. Geophys. Res. Lett., 34, L20401, doi:10.1029/2007GL031088.

Beljaars, A. C. M., P. Viterbo, and M. J. Miller, 1996: The anomalous rainfall over the United States during July 1993: Sensitivity to land surface parameterization and soil moisture anomalies. Mon. Wea. Rev., 124, 362-383.

Bindlish, R., T. J. Jackson, E. Wood, H. Gao, P. Starks, D. Bosch, and V. Lakshmi, 2003: Soil moisture estimates from TRMM Microwave Imager observations over the Southern United States. Remote Sens. Environ., 85, 507-515.

Crow, W. T., 2003: Correcting land surface model predictions for the impact of temporally sparse rainfall rate measurements using an ensemble Kalman filter and surface brightness temperature observations. J. Hydrometeor., 4, 960-973.

— , and R. H. Reichle, 2008: Comparison of adaptive filtering techniques for land surface data assimilation. Water Resour. Res., 44, W08423, doi:10.1029/2008WR006883.

_ estimating observation and model error parameters for soil moisture data assimilation. Water Resour. Res., 46, W12519, doi:10.1029/2010WR009402.

—, D. Entekhabi, R. D. Koster, and R. H. Reichle, 2006: Multiple spaceborne water cycle observations would aid modeling. Eos, Trans. Amer. Geophys. Union, 87, doi:10.1029/2006EO150002.

de Jeu, R. A. M., W. Wagner, T. R. H. Holmes, A. J. Dolman, N. C. van de Giesen, and J. Friesen, 2008: Global soil moisture patterns observed by space borne microwave radiometers and scatterometers. Surv. Geophys., 29, 399-420, doi:10.1007/ s1071200890440.

de Wit, A. M., and C. A. van Diepen, 2007: Crop model data assimilation with the ensemble Kalman filter for improving regional crop yield forecasts. Agric. For. Meteor., 146, 38-56, doi:10.1016/j.agrformet.2007.05.004.

Dirmeyer P., X. Gao, and T. Oki, 2002: The Second Global Soil Wetness Project (GSWP-2) science and implementation plan. GEWEX News, No. 37, International GEWEX Project Office, Silver Spring, MD, 69 pp.

Drusch, M., 2007: Initializing numerical weather prediction models with satellite-derived surface soil moisture: Data assimilation experiments with ECMWF's Integrated Forecast System and the TMI soil moisture data set. J. Geophys. Res., 112, D03102, doi:10.1029/2006JD007478.

, E. F. Wood, and H. Gao, 2005: Observation operators for the direct assimilation of TRMM microwave imager retrieved soil moisture. Geophys. Res. Lett., 32, L15403, doi:10.1029/ 2005 GL023623.

—, K. Scipal, P. de Rosnay, G. Balsamo, E. Andersson, P. Bougeault, and P. Viterbo, 2009: Towards a Kalman filter based soil moisture analysis system for the operational ECMWF Integrated Forecast System. Geophys. Res. Lett., 36, L10401, doi:10.1029/2009GL037716.

Entekhabi, D., and Coauthors, 2010a: The Soil Moisture Active and Passive (SMAP) Mission. Proc. IEEE, 98, 704-716, doi:10.1109/JPROC.2010.2043918.

—, R. H. Reichle, R. D. Koster, and W. T. Crow, 2010b: Performance metrics for soil moisture retrievals and application requirements. J. Hydrometeor., 11, 832-840.

Gao, H., E. F. Wood, T. J. Jackson, M. Drusch, and R. Bindlish, 2006: Using TRMM/TMI to retrieve surface soil moisture over the southern United States from 1998 to 2002. J. Hydrometeor., 7, 23-38.

,-- , M. Drusch, and M. McCabe, 2007: Copula-derived observation operators for assimilating TMI and AMSR-E retrieved soil moisture into land surface models. J. Hydrometeor., 8, 413-429.

Gottschalck, J., J. Meng, M. Rodell, and P. Houser, 2005: Analysis of multiple precipitation products and preliminary assessment of their impact on Global Land Data Assimilation System land surface states. J. Hydrometeor., 6, 573-598.

Guo, Z., P. A. Dirmeyer, Z.-Z. Hu, X. Gao, and M. Zhao, 2006: Evaluation of the Second Global Soil Wetness Project soil moisture simulations: 2 . Sensitivity to external meteorological forcing. J. Geophys. Res., 111, D22S03, doi:10.1029/ 2006JD007845.

Higgins, R. W., W. Shi, E. Yarosh, and R. Joyce, 2000: Improved United States precipitation quality control system and analysis. NCEP/Climate Prediction Center Atlas, NOAA, Vol. 7. [Available online at http://www.cpc.ncep.noaa.gov/research_ papers/ncep_cpc_atlas/7/index.html.]

Huffman, G. J., and Coauthors, 1997: The Global Precipitation Climatology Project (GPCP) combined precipitation dataset. Bull. Amer. Meteor. Soc., 78, 5-20.

- and Coauthors, 2007: The TRMM Multisatellite Precipitation Analysis (TMPA): Quasi-global, multiyear, combinedsensor precipitation estimates at fine scales. J. Hydrometeor., $\mathbf{8}$, 38-55.

Jackson, T. J., 1993: Measuring surface soil moisture using passive microwave remote sensing. Hydrol. Processes, 7, 139-152.

- , R. Hurkmans, A. Hsu, and M. H. Cosh, 2004: Soil moisture algorithm validation using data from the Advanced Microwave Scanning Radiometer (AMSR-E) in Mongolia. Ital. J. Remote Sens., 30 (31), 39-52.

_ and Coauthors, 2010: Validation of Advanced Microwave Scanning Radiometer Soil Moisture Products. IEEE Trans. Geosci. Remote Sens., 48, 4256-4272, doi:10.1109/TGRS.2010. 2051035.

Joyce, R. J., J. E. Janowiak, P. A. Arkin, and P. Xie, 2004: CMORPH: A method that produces global precipitation estimates from passive microwave and infrared data at high spatial and temporal resolution. J. Hydrometeor., 5, 487-503.

Kato, H., M. Rodell, F. Beyrich, H. Cleugh, E. van Gorsel, H. Liu, and T. P. Meyers, 2007: Sensitivity of land surface simulations to model physics, land characteristics, and forcings, at four CEOP sites. J. Meteor. Soc. Japan, 85, 187-204.

Kerr, Y. H., and Coauthors, 2010: The SMOS mission: New tool for monitoring key elements of the global water cycle. Proc IEEE, 98, 666-687.

Koster, R. D., M. J. Suarez, A. Ducharne, M. Stieglitz, and P. Kumar, 2000: A catchment-based approach to modeling land surface processes in a general circulation model 1. Model structure. J. Geophys. Res., 105 (D20), 24 809-24 822. 
_ , T. Bell, R. H. Reichle, M. Suarez, and S. Schubert, 2008: Using observed spatial correlation structures to increase the skill of subseasonal forecasts. Mon. Wea. Rev., 136, 1923-1939.

Li, F., W. T. Crow, and W. P. Kustas, 2010: Towards the estimation root-zone soil moisture via the simultaneous assimilation of thermal and microwave soil moisture retrievals. Adv. Water Resour., 33, 201-214.

Liu, Y. Y., R. M. Parinussa, W. A. Dorigo, R. A. M. de Jeu, W. Wagner, A. I. J. van Dijk, M. F. McCabe, and J. P. Evans, 2010: Developing an improved soil moisture dataset by blending passive and active microwave satellite-based retrievals. Hydrol. Earth Syst. Sci. Discuss., 7, 6699-6724, doi:10.5194/ hessd-7-6699-2010.

Mahfouf, J. F., 2010: Assimilation of satellite-derived soil moisture from ASCAT in a limited-area NWP model. Quart. J. Roy. Meteor. Soc., 136, 784-798.

Njoku, E. G., 2010: AMSR-E/Aqua L2B surface soil moisture, ancillary params, and QC EASE-Grids. National Snow and Ice Data Center, Boulder, $\mathrm{CO}$, digital media. [Available online at http://nsidc.org/data/amsre/data_summaries/index.html.]

_ , and D. Entekhabi, 1996: Passive microwave sensing of soil moisture. J. Hydrol., 184, 101-129.

Njoku, E., T. Jackson, V. Lakshmi, T. Chan, and S. Nghiem, 2003: Soil moisure retrieval from AMSR-E. IEEE Trans. Geosci. Remote Sens., 41, 215-229.

Owe, M., R. de Jeu, and J. Walker, 2001: A methodology for surface soil moisture and vegetation optical depth retrieval using the microwave polarization difference index. IEEE Trans. Geosci. Remote Sens., 39, 1643-1654.

,-- , and T. Holmes, 2008: Multisensor historical climatology of satellite-derived global land surface moisture. J. Geophys. Res., 113, F01002, doi:1029/2007JF000769.

Parajka, J., V. Naeimi, G. Blöschl, W. Wagner, R. Merz, and K. Scipal, 2006: Assimilating scatterometer soil moisture data into conceptual hydrologic models at the regional scale. Hydrol. Earth Syst. Sci., 10, 353-368, doi:10.5194/hess-10-353-2006.

Reichle, R. H., and R. D. Koster, 2003: Assessing the impact of horizontal error correlations in background fields on soil moisture estimation. J. Hydrometeor., 4, 1229-1242.

— and - 2004: Bias reduction in short records of satellite soil moisture. Geophys. Res. Lett., 31, L19501, doi:10.1029/ 2004GL020938.

_ D. B. McLaughlin, and D. Entekhabi, 2002: Hydrologic data assimilation with the ensemble Kalman filter. Mon. Wea. Rev., 130, 103-114.

- R. D. Koster, J. Dong, and A. A. Berg, 2004: Global soil moisture from satellite observations, land surface models, and ground data: Implications for data assimilation. J. Hydrometeor., 5, 430-442.

,-- , P. Liu, S. P. P. Mahanama, E. G. Njoku, and M. Owe, 2007: Comparison and assimilation of global soil moisture retrievals from the Advanced Microwave Scanning Radiometer for the Earth Observing System (AMSR-E) and the Scanning Multichannel Microwave Radiometer (SMMR). J. Geophys. Res., 112, D09108, doi:10.1029/2006JD008033.

— W. T. Crow, and C. L. Keppenne, 2008a: An adaptive ensemble Kalman filter for soil moisture data assimilation. Water Resour. Res., 44, W03423, doi:10.1029/2007WR006357.

, R. D. Koster, H. Sharif, and S. P. P. Mahanama, 2008b: Contribution of soil moisture retrievals to land data assimilation products. Geophys. Res. Lett., 35, L01404, doi:10.1029/ 2007 GL031986.

— , S. V. Kumar, S. P. P. Mahanama, R. D. Koster, and Q. Liu, 2010: Assimilation of satellite-derived skin temperature observations into land surface models. J. Hydrometeor., 11, $1103-1122$

Rienecker, M. M., and Coauthors, 2008: The GEOS-5 Data Assimilation System-Documentation of versions 5.0.1, 5.1.0, and 5.2.0. Technical Report Series on Global Modeling and Data Assimilation, Vol. 27, NASA, 118 pp. [Available online at http://gmao.gsfc.nasa.gov/pubs/docs/Rienecker369.pdf.]

Robock, A., C. A. Schlosser, K. Y. Vinnikov, N. A. Speranskaya, and J. K. Entin, 1998: Evaluation of AMIP soil moisture simulations. Global Planet. Change, 19, 181-208.

Schaefer, G. L., M. H. Cosh, and T. J. Jackson, 2007: The USDA Natural Resources Conservation Service Soil Climate Analysis Network (SCAN). J. Atmos. Oceanic Technol., 24, 20732077.

Scipal, K., M. Drusch, and W. Wagner, 2008: Assimilation of a ERS scatterometer derived soil moisture index in the ECMWF numerical weather prediction system. Adv. Water Resour., 31, 1101-1112, doi:10.1016/j.advwatres.2008.04.013.

Smith, E., and Coauthors, 2007: The international Global Precipitation Measurement (GPM) program and mission: An overview. Measuring Rainfall from Space: EURAINSAT and the Future, V. Levizzani and F. J. Turk, Eds., Springer, $611-653$

Srinivasan, G., and Coauthors, 2000: Soil moisture simulations in revised AMIP models. J. Geophys. Res., 105 (D21), 26 63526644.

Wagner, W., G. Lemoine, and H. Rott, 1999: A method for estimating soil moisture from ERS scatterometer and soil data. Remote Sens. Environ., 70, 191-207.

Xie, P., and P. A. Arkin, 1997: Global precipitation: A 17-year monthly analysis based on gauge observations, satellite estimates, and numerical model outputs. Bull. Amer. Meteor. Soc., 78, 2539-2558.

, J. E. Janowiak, P. A. Arkin, R. Adler, A. Gruber, R. Ferraro, G. J. Huffman, and S. Curtis, 2003: GPCP pentad precipitation analyses: An experimental dataset based on gauge observations and satellite estimates. J. Climate, 16, $2197-$ 2214. 